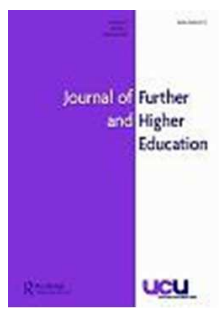

\title{
Epistemic Beliefs and Academic Performance Across Soft and Hard Disciplines in the First Year of College
}

\begin{tabular}{|r|l|}
\hline Journal: & Journal of Further and Higher Education \\
\hline Manuscript ID & CJFH-2016-0012 \\
\hline Manuscript Type: & Original Paper \\
\hline Keywords: & $\begin{array}{l}\text { personal epistemology, epistemic belief, academic performance, } \\
\text { disciplinary difference, higher education }\end{array}$ \\
\hline
\end{tabular}

SCHOLARONE ${ }^{\text {IM }}$

Manuscripts 


\title{
Epistemic Beliefs and Academic Performance Across Soft and Hard Disciplines in the First Year of College
}

\begin{abstract}
Mature epistemic beliefs underlie higher-order thinking and learning outcomes. Previous studies have established that epistemic beliefs predict taskspecific learning outcomes. However, there is mixed evidence regarding the relationships between such beliefs and course-level academic performance. This study investigated whether disciplinary type ("soft" vs. "hard") could account for the mixed findings. A prospective survey was conducted among 1366 university students enrolled in "soft" (design, psychology, and law) and "hard" disciplines (engineering, biotechnology, and pharmacy). Beliefs about the uncertainty of knowledge, the subjectivity of knowledge, and authority justification were measured before the start of semester. Findings indicated that while subjectivity belief was not associated with GPA in the soft disciplines, it negatively predicted GPA in the hard disciplines. Uncertainty belief, but not authority belief, was associated with GPA in both disciplines. Hence, the relations between some epistemic beliefs and academic performance may depend on the nature of the discipline.
\end{abstract}

Keywords: personal epistemology, epistemic belief, academic performance, disciplinary difference, higher education 